\title{
A STUDY ON THE CAUSES OF STUDENTS' DISRUPTIVE BEHAVIOUR IN PRIMARY SCHOOL AND GYMNASIUM IN THE ROMANIAN EDUCATIONAL CONTEXT
}

\author{
Luiza Enachi-Vasluianu ${ }^{1}$, Flavia Malureanu ${ }^{2}$
}

\begin{abstract}
School today lays emphasis on developing skills which should ensure for children solid integration into society. Discipline is one of the skills which must be underlain in school. An efficient approach of discipline teaches students to assume responsibility and self-discipline. However, there have always been children who, for various reasons, break the discipline rules. Practice in school has shown that the factors that contribute to disruptive behaviour are connected to continuous changes in the social environment, curriculum idiosyncrasies, individual differences, the teacher-student relationship,the teacher's act in classroom, the relationships among children in classroom / school, antipathy towards school, the need for social recognition, social isolation, impulsive behaviour, affective transfer, aggression in classroom / school, anxiety, absence of academic success, boredom, etc.

Our paper limits the research to a series of causes of students' disruptive behaviour in primary school and gymnasium specific to the Romanian educational context. The data gathered provides information on the perspectives of teachers regarding the most relevant causes that affect discipline in classrooms. Their acknowledgement may be of help as it diminishes the time, the energy and the stress required to deal with inappropriate behaviour displayed by selecting efficient strategies to counterbalance it beforehand.
\end{abstract}

UDC Classification: 373; DOI: http://dx.doi.org/10.12955/cbup.v6.1258

Keywords: disruptive student behaviour, causes of rule breaking, discipline, social integration

\section{Introduction}

School has a decisive role in developing the socializing skills of students, that is why teachers, as educational agents, should use various strategies to promote learning and good behaviour. However, daily practice shows that one of the current challenges teachers have to deal with is the problem of discipline in the classroom. In order for teachers to influence most effectively, shape or improve the conduct of students, they should become familiarised with the possible causes that may generate disruption in students' behaviour. Relying on specific literature and school practice, this paper focuses on a series of relevant causes that determine disruptive behaviour in students, all in strict reference to the Romanian educational environment.

\section{Literature review}

In the Romanian educational system, the curriculum is often very complex, with disciplines that have too much content, at the school levels targeted by our research. This creates high pressure on the children, who make considerable intellectual efforts to get good results. At gymnasium the pressure is much higher as the high school entrance grade represents a mean between $20 \%$ of the four-year gymnasium general grade and $80 \%$ of the grade obtained in the national high school entrance examination. This makes the student work hard in order to get good marks. On the other hand, because of fatigue, the school competitive atmosphere, the efforts of students sometimes can determine outbursts that can lead to situations of educational crisis.

In Romanian schools, competition is promoted as a form of academic progress and as a form of maintaining a high study motivation level. By promoting competition, the students are determined to establish for themselves higher aspirations, to persevere in getting their goals and be prepared to deal with the conditions of a society organized on principles of competition. In this context, students often 'hunt' for grades and need recognition of their merits from teachers and colleagues. This state of affairs, although counterbalanced by the use of interactive methods based on work in groups, which do not exclude competitive atmosphere among teams, leads to the appearance of some tensions which are considered by the teachers involved in the focus-groups as sources of disruptive behaviours. At the same time, competition has a series of negative effects such as an increase in aggressive, hostile behaviours, of conflicts and attitudes of suspicion and opposition. The exaggerate competition generates frustration, anxiety, insecurity for children with medium and low school results, which tend to abandon work (Sălăvăstru, 2004).

\footnotetext{
${ }^{1}$ Faculty of Psychology and Educational Sciences, University of Bucharest, Romania, vasluianu_luiza@yahoo.com

${ }^{2}$ Faculty of Psychology and Educational Sciences, University of Bucharest, Romania, flaviamalureanu@yahoo.com
} 
The competitive atmosphere may trigger academic progress, but sometimes, students get involved in real conflicts with their peers in order to obtain better school results. The competitive process is characterised through low interaction among students, lack of communication or delivery of false information, and lack of mutual trust. All these lead to a low cohesion of the group, the development of individualistic attitudes, tensions among the students which can accede to school violence.

Aggression in school, as a form of disruptive behaviour, is a phenomenon which seems to increase in display: from verbal aggression, moderate aggressive gestures to fights among students. The teachers involved in the study provided a few examples of aggressive manifestations: verbal impertinence, visual confrontation, irony, calling names, teasing, pushing, slapping etc. These aggressive behaviours of students have multiple causes such as family problems (divorced parents, poverty), families with conflictual climates, overly indulgent adult family members, wrong behaviour models learned within the family, entourage, age specific characteristics (the need to draw attention, to impress, to affirm masculinity or supremacy, in the case of girls), stress, injustice, piled-up classes, the absence of clear rules of behaviour supported by the exposure of possible consequences etc. (Şoitu, Havarneanu, 2001).

Some disruptive behaviours derive from the nature of relationships the participants develop. Each student has ample, complex sets of values. If these values are in accordance with the goals of the educational process, they create a favourable climate for the development of the educational activities. On the other hand, if these values are in disagreement, the conflicts that arise represent obstacles for a good educational environment. The conflict of values is set at different levels: moral values, aesthetic values, common life values etc. (Sălăvăstru, 2004). The conflict of values between teachers and students derive, most of the times, from the family and cultural environment they were brought up into. Acknowledging the structure and the values of a student's family gives the teacher the possibility to anticipate and interpret adequately the student's behaviours and attitudes. Conflicts can also be generated at the level of common life values. Generally speaking, the young generation is the advocate of maximal thought and speech freedom, while school through education lays emphasis on compliance, social guidance, observance of norms. Students interpret all these as attempts to impede their individual freedom and as restrictions to their individual initiative. The student-teacher relationship is greatly affected when students perceive school requests as strategies of constraint in order to force them to adopt specific behaviours. As such, students react to school rules, to uniforms, and to pre-established hierarchy. All these can amount to conflicts which are difficult to solve if the teacher ignores them or is unable to deal with them.

The teacher-student relationship displays situations which determine disruptive behaviour in students, as a form of authority defiance, or a manifestation of frustration or discontent. For instance, teachers do not have the patience to listen to their queries during the classes, are aloof to students, impose an authoritative style of teaching, use teaching strategies that are not attractive to students, etc. These problematic situations derive from the gap between the expectations of students and the current school practice. Students expect a relationship based on negotiation, independence, initiative and empathy in relation to their teachers, while the teachers want a relationship based on dependence, control, authority and conformity (Jigău, 2006).

Students with poor results are inhibited when teachers label them as problem-students. They repress their anger when they suffer injustice or become indifferent when they are treated with indifference. Repeated psychological violence against students can lead to a change of attitude towards the teacher and school, in general. Students can develop lack of self-confidence, a lack of (self-)discipline or become discouraged, attitudes which lead to refusal to communicate, passivity during the classes, disruptions of the teaching process, and hostile displays of behaviour (Şoitu, Havarneanu, 2001).

The relationships among children of various ages are not always positive as they can be pervaded by prejudices, stereotypes, different values, attitudes, expectations, preconceptions etc. Sometimes, children are marginalised by their colleagues from various reasons such as economic, social, academic results, bullying, envy, aggression etc. The teachers involved in the research mention that the disruptive behaviours based on dysfunctional relationships among students manifest verbally and physically with medium intensity and without severe consequences.

Educational communication displays a series of dysfunctions, objective or subjective, which impede the communicational act. Acknowledging them is necessary if we want to diminish or remove their 
effects. Dysfunctions in communication are present in verbal communication, oral and written, and in the nonverbal and paraverbal communications. Research (Mălureanu, Enachi-Vasluianu, 2014, 2017) has emphasized the impact of several causes of verbal dysfunctions such as lexical selection, incompatibility of a teacher's and a student's repertoires (mutual adjustment to the partner in terms of cognitive and linguistic experience), language which is not adapted to the level of understanding of students, routine language which affects receptivity, concise educational messages, students' difficulties with oral and written expressions, the slow/ fast rhythm adopted in communication, the excessive use of figures of speech, strict, restrictive norms of verbal conduct established by the teacher, semantic dysfunctions, ambiguity of language etc. Nonverbal language is a form of disruptive behaviour manifestation when students display exaggerate or obscene gestures contrary to civilized behaviour, mimicry of contempt, defiance etc. The paraverbal language can also be source of disruptive behaviour as the partner of communication can change a message through tonality from seriousness to irony, threat, indifference, stupefaction, anguish etc. Speaking in a high or simply superior pitch transmits the interlocutor an aggressive subliminal message, which will make them bestow a negative connotation on the relationship (Dinu, 2004). Teachers involved in this research state that communication problems often constitute causes of students' disruptive behaviours.

In our opinion, the personal problems that can affect the behaviour of students can be classified into physical problems (health issues, fatigue, possible sensory or neuromotor system disabilities), psychological problems (low motivation, deficiency / lacunae in will education, exaggerate affective manifestations, emotional imbalance, slow rhythm of psychic development, inferiority complexes etc.), family problems (family with low intellectual level, excessive protection and guidance of children, parents' lack of interest in their children's education, deficient communication between parents and children, negative models of behaviour in the family, tense family climate etc.), problems in the school environment (theoretical and practical overstrain, fast rhythm of school activities, prolonged school stress, insufficient psychopedagogical instruction of teachers), relationship problems (difficulties of integration into groups), social problems (change of residence which imply moving the child to a new school and their interaction with a new environment, children living in neighbourhoods with constant display of antisocial behaviour, international migration, repatriation etc.).

\section{Methodology of Research}

\section{Objectives}

The research objectives are a) to identify the causes of the disruptive behaviour of students at primary school and gymnasium, b) to perform a descriptive analyses of the selected elements to determine a hierarchy in two school levels. In the Romanian educational system primary school lasts five years, with students aged from 6 to 11. The children at this school stage are taught by the same teacher, except for physical education and foreign languages classes where they have different teachers. The next level is the four-year gymnasium, with students aged 11 to 15 . Each discipline is taught by a different teacher.

\section{Participants}

The sample involved in the research consisted of 100 teachers from Vrancea County, Romania: 50 primary school teachers and 50 gymnasium teachers. Their experience in the field of education varied from 7 to 30 years.

\section{Research instrument}

One of the methods used for the research was the questionnaire-based investigation. The questionnaire was built based on specific literature and focus-group discussions with teachers from the school levels already mentioned. The specific literature together with these methods enabled the identification of a series of causes of the disruptive behaviour of students in primary school and gymnasium transposed into the following items: idiosyncrasies of the curriculum, competitive atmosphere, conflict of values, teacher-student relationship, student-student relationship, aggressive behaviour in the classroom, absence of academic success, dysfunctions in the educational communication, personal problems.

The respondents circled one variant of a five-step scale: (1) to a very low extent, (2) to a low extent, (3) to an average extent, (4) to a large extent, (5) to a very large extent. The answers showed the relevance for each item as causes the disruptive behaviour of students in primary school and gymnasium in the Romanian educational context. 


\section{Results and Discussion}

For the descriptive analyses, we used SPSS software and a t-test for the independent samples.

\begin{tabular}{|c|c|c|c|}
\hline & Items of causes of students' disruptive behaviour & $\begin{array}{c}\text { Primary } \\
\text { Mean (std. dev.) }\end{array}$ & $\begin{array}{c}\text { Gymnasium } \\
\text { Mean (std. dev.) }\end{array}$ \\
\hline & 1. idiosyncrasies of the curriculum & $3.64(0.563)$ & $4.82(0.756)$ \\
\hline & 2. competitive atmosphere & $4.26(0.618)$ & $4.86(0.438)$ \\
\hline & 3. conflict of values & $4.52(0.789)$ & $4.36(0.668)$ \\
\hline & 4. teacher-student relationship & $4.10(0.832)$ & $4.04(0.872)$ \\
\hline & 5. student-student relationship & $4.78(0.418)$ & $4.08(0.724)$ \\
\hline & 6. children's aggressive behavior in the classroom & $4.66(0.604)$ & $4.28(1.118)$ \\
\hline & 7. absence of academic success & $4.22(0.840)$ & $3.88(0.654)$ \\
\hline & 8. dysfunctions in educational communication & $4.34(0.767)$ & $4.76(0.624)$ \\
\hline & 9. personal problems & $4.46(0.820)$ & $4.16(0.484)$ \\
\hline
\end{tabular}

Using the means obtained in Table 1 we have realised a hierarchy of the causes of the disruptive behaviour of students in the two school levels as presented in Table 2. As such, the indicator that was ranked $1^{\text {st }}$ was considered highly relevant as a cause of disruptive behaviour in students, whereas the item in the $9^{\text {th }}$ rank was perceived as less relevant.

\begin{tabular}{|l|l|l|l|}
\hline \multicolumn{3}{|c|}{ Table 2: Description of hierarchy of causes of disruptive behaviour in students. } \\
\hline Rank & \multicolumn{1}{|c|}{ Primary } & \multicolumn{1}{c|}{ Gymnasium } \\
\hline $\mathbf{1 .}$ & student-student relationship & competitive atmosphere \\
\hline $\mathbf{2 .}$ & children's aggressive behavior in the classroom & idiosyncrasies of the curriculum \\
\hline $\mathbf{3 .}$ & conflict of values & dysfunctions in educational communication \\
\hline $\mathbf{4 .}$ & personal problems & conflict of values \\
\hline $\mathbf{5 .}$ & dysfunctions in educational communication & children's aggressive behavior in the classroom \\
\hline $\mathbf{6 .}$ & competitive atmosphere & personal problems \\
\hline $\mathbf{7 .}$ & absence of academic success & student-student relationship \\
\hline $\mathbf{8 .}$ & teacher-student relationship & teacher-student relationship \\
\hline $\mathbf{9 .}$ & idiosyncrasies of the curriculum & absence of academic success \\
\hline
\end{tabular}

Source: Authors

The means obtained in primary school vary between 4.78 and 3.64 , whereas in the gymnasium they vary between 4.86 and 3.88. For primary school, the top three ranks are for the following items: student-student relationship $(\mathrm{m}=4.78)$, children's aggressive behaviour in classroom $(\mathrm{m}=4.66)$, conflict of values $(\mathrm{m}=4.52)$. For gymnasium, the top three ranks are for competitive atmosphere triggered by the specifics of the Romanian educational system $(\mathrm{m}=4.86)$, idiosyncrasies of the curriculum $(\mathrm{m}=4.82)$, dysfunctions in the educational communication $(\mathrm{m}=4.76)$.

The item student-student relationship rated highest for primary school as this is the period in which the relationships among students diversify based on subjective criteria, most of the times. During this period of five years children learn to know themselves better, learn new behaviours which are not always desired. The relationships among primary school students are not constant most of the times, as they might vary from friendship to maliciously ignoring the other. Thus, when the relationships are not positive, children disobey the discipline rules, involve the teacher in their subjective conflicts, and sometimes even the parents get involved thus amplifying the disagreement. The conflicts between students in primary school are usually superficial, but, unfortunately, most of the time they succeed in disrupting the teaching process.

The lowest mean in primary school was registered for curriculum idiosyncrasies as teachers who participated in the debates in focus-groups consider that the knowledge, attitudes and skills are usually formed using successful strategies by the same teacher who gets to know their students very well during the five-year primary school stage and adjusts the didactic tools in such a way that disruptive behaviour should affect the didactic activity to a low extent.

In gymnasium students are more interested in getting good grades as their general mark counts to a certain percentage for their high school entrance examination. The persistent interest in grades 
generates competition and comparison with other peers' marks. As a result, some of the times, there can appear situations that may degenerate into inappropriate behaviour or tension among students. The lowest mean at the same school level was registered for the absence of academic success as the students with poor results are less interested in competitions or comparisons with their peers, they do not get involved actively in the learning process and they usually do not manifest disruptive behaviours so as not to draw attention upon themselves, in terms of negative consequences from their peers and teachers.

We set the significance level to 0.05 and we applied the T-test for the independent groups in order to determine the differences of appreciations between the two groups. Statistically significant differences were registered for seven items $(\mathrm{p}<0.05)$, which shows divergence of opinions among the respondents at the two school levels. These items are: student-student relationship, children's aggressive behaviour in the classroom, personal problems, dysfunctions in the educational communication, competitive atmosphere triggered by the specifics of the Romanian educational system, idiosyncrasies of the curriculum, absence of academic success. For four of these items the means are higher for primary school than for gymnasium (student-student relationship $(\mathrm{m}=4.78)$, children's aggressive behaviour in the classroom $(\mathrm{m}=4.66)$, personal problems $(\mathrm{m}=4.46)$, absence of academic success $(\mathrm{m}=4.22)$ ), which demonstrates they have a higher impact as causes of disruptive behaviour at this school level. For the other three items, the means are higher at gymnasium than at primary school (dysfunctions in the educational communication $(\mathrm{m}=4.76)$, competitive atmosphere $(\mathrm{m}=4.86)$, curriculum idiosyncrasies $(\mathrm{m}=4.82)$ ). This means they carry a greater relevance as causes of disruptive behaviour at gymnasium. There were not registered statistically significant differences ( $p>0.05)$ only for two items: teacher-student relationship, conflict of values, thus proving convergence of opinions of the two categories of the teachers questioned.

\section{Conclusions}

Discipline is a key ingredient of successful didactic activity. School, in cooperation with family must teach (self-)discipline and create a climate that helps students develop the skills required for responsible behaviour. However, practice shows that disruptive behaviour is a major concern in schools nowadays. The strategies used to cope with this problem vary from the promotion of prosocial behaviours such as empathy, respect for diversity, tolerance etc., and adjoining interventions from teachers, counsellors, students, families who should elaborate strategies, coordinate and monitor the specific activities. On the other hand, the reactions of teachers to indiscipline provide students with models of behaviour. That is why teachers should have a good knowledge of psychology and classroom management skills necessary for good management of the problematic situations.

The present research provides information on the possible causes of the disruptive behaviour of students at primary and gymnasium school levels. The items described in the research were selected by taking into account the specifics of the present Romanian educational context. Although analysed individually, the causes of disruptive behaviour can act separately or in combinations determined by the particular situation. The data gathered draw attention on the aspects the teachers must focus on in order to limit and prevent disruptive behaviour. They should use this information and adjust it to the situational contexts from their classrooms. The research could be completed with the identification of a series of successful strategies of prevention and limitation of the disruptive behaviour of students already identified.

\section{References}

Dinu, M. (2004). Comunicarea. Repere fundamentale. București: Algos.

Jigău, M. (2006). Prevenirea şi combaterea violenței în școală. Buzau: Alpha MDN.

Mălureanu, F., Enachi-Vasluianu, L. (2014). A Comparative Analysis of the Linguistic Dysfunctions in the Didactic Communication.

Retrieved March 4, 2018, from https://www.sciencedirect.com/science/article/pii/S1877042814022940

Mălureanu, F., Enachi-Vasluianu, L. (2017). Nonverbal and paraverbal aspects in teacher's communication perceived as hostile by students.

Retrieved March 23, 2018, from https://www.scribd.com/document/360886718/Proceedings-of-ICVL-2017-ISSN-18448933-ISI-Proceedings

Sălăvăstru, D. (2004). Psihologia educației. Iași: Polirom.

Şoitu, L., \& Havarneanu C. (2001). Agresivitatea în şcoală. Iaşi: Institutul European. 